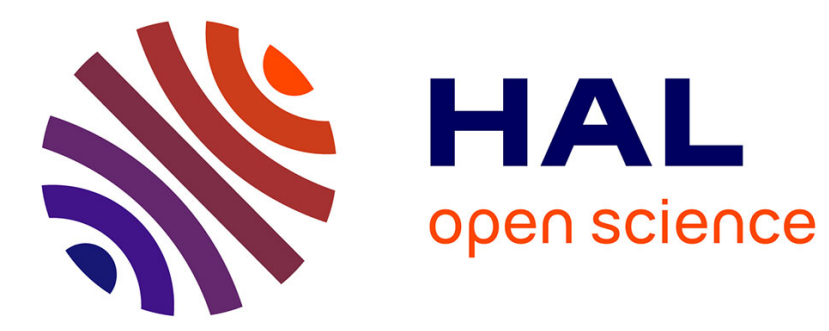

\title{
Sedimentary record of rapid climatic variability in the North Atlantic Ocean during the Last Glacial Cycle
} Elsa Cortijo, Pascal Yiou, Laurent Labeyrie, Michael Cremer

\section{To cite this version:}

Elsa Cortijo, Pascal Yiou, Laurent Labeyrie, Michael Cremer. Sedimentary record of rapid climatic variability in the North Atlantic Ocean during the Last Glacial Cycle. Paleoceanography, 1995, 10 (5), pp.911-926. 10.1029/95PA02021 . hal-03002474

\section{HAL Id: hal-03002474 https://hal.science/hal-03002474}

Submitted on 5 Feb 2021

HAL is a multi-disciplinary open access archive for the deposit and dissemination of scientific research documents, whether they are published or not. The documents may come from teaching and research institutions in France or abroad, or from public or private research centers.
L'archive ouverte pluridisciplinaire HAL, est destinée au dépôt et à la diffusion de documents scientifiques de niveau recherche, publiés ou non, émanant des établissements d'enseignement et de recherche français ou étrangers, des laboratoires publics ou privés. 


\title{
Sedimentary record of rapid climatic variability in the North Atlantic Ocean during the last glacial cycle
}

\author{
Elsa Cortijo, ${ }^{1}$ Pascal Yiou, ${ }^{2}$ Laurent Labeyrie, ${ }^{1,3}$ and Michel Cremer ${ }^{4}$
}

\begin{abstract}
Comparisons between a Greenland ice core isotopic record and marine sediment grey level records of the North Atlantic Ocean show that rapid temperature variations witnessed by the ice core (Dansgaard-Oeschger events) during the last glacial period can also be detected in marine sediments. This shows that the resolution obtained in marine cores can be sufficiently high to record rapid climatic fluctuations. Several spectral analyses of those grey level marine records consistently indicate that significative fluctuations of the climatic response exist with periodicities of 5 to $1 \mathrm{kyr}$ in addition to orbital forcing. These high frequencies are close to those predicted by various dynamic ocean models.
\end{abstract}

\section{Introduction}

The climatic system is clearly recognized to be continually variable, on all timescales [Mitchell, 1976]. Many different physical processes can contribute to climatic variability on one or another timescale. Climatic variance on the orbital timescale [Hays et al., 1976] is centered around periodicities of 100,40 , and $20 \mathrm{kyr}$ (100 kyr corresponds to the dominant periodicity of middle-late Quaternary glaciations; 40 and 20 kyr are associated with variations of obliquity and precession of the Earth, respectively). Orbital changes in insolation were gradual and occurred over several thousand years. However, there is now abundant evidence for climatic changes on millenial timescales which cannot be accounted for only by orbital variations and must be explained also by internal oscillations of the system or interactions between the orbital forcing and internal mechanisms. Ice core records obtained in central Greenland reveal that the last glacial period was extremely unstable [Dansgaard et al., 1982; Greenland Ice core Project (GRIP) Members, 1993]. Those large and abrupt climatic transitions, the Dansgaard-Oeschger events, lasted a few decades. Such high-frequency oscillations were also detected in the deuterium isotope profile ( $\delta D)$ of the Vostok ice core [Yiou et al., 1994]. The oceanic signal has usually been considered to be too rough to detect such variability because of the bioturbation effects. The postdepositional mixing of sediment layers by biological activity, the bioturbation effect,

\footnotetext{
${ }^{1}$ Centre des Faibles Radioactivités, Laboratoire mixte CNRS/CEA, Gif-sur-Yvette, France.

${ }^{2}$ Laboratoire de Modélisation du Climat et de l'Environnement, CEA, Gif-sur-Yvette, France.

${ }^{3}$ Also at Département des Sciences de la Terre, Université de Paris-Sud/Orsay, Orsay, France.

${ }^{4}$ Département de Géologie et d'Océanographie, Université de Bordeaux 1, Talence, France.
}

Copyright 1995 by the American Geophysical Union.

Paper number 95PA02021.

0883-8305/95/95PA-02021\$10.00 tends to smooth the rapid climatic events but does not completely remove them as shown here. In North Atlantic cores above $40^{\circ} \mathrm{N}$, the continual mixing of the sediment by benthic activity is estimated to be less than $5 \mathrm{~cm}$ [Griggs et al., 1969]. Another modification in the sediment can be due to occasional large burrows which transport sediment into lower levels. This kind of bioturbation can easily be identified during the treatment of the core. Hence the purpose of our paper is to determine the high-frequency part of the climatic variability contained in marine sediments. First, we compare marine sediment and ice core records. Second, we conduct spectral analyses of marine sediment records. We show that marine sediments can detect rapid variations of the climatic system down to periods of $1.5 \mathrm{kyr}$. Some of these variations may be global, but others are specific to the North Atlantic in relation with Greenland.

\section{Material and Method for Measurements of Sedimentary Reflectance}

We selected cores from 10 sites in the North Atlantic Ocean located between $41^{\circ}$ and $60^{\circ} \mathrm{N}$ and between $20^{\circ}$ and $30^{\circ} \mathrm{W}$ (Table 1 and Figure 1). Cores were taken from various depths of each side of the Mid-Atlantic Ridge above the carbonate compensation depth. In all cores, the grey reflectance of surface sediment was measured following the method developed by Bond et al. [1992a].

The cores were digitized by sections of $75 \mathrm{~cm}$ in length with a tri-CCD (Charged Coupled Device) color camera. The lighting is constituted by two neon glow lamps. For each core, we obtain an image by concatenation of all of the $75-\mathrm{cm}$ sections. In this image, one pixel represents approximately 1.3 mm of sediment. The theoretical temporal resolution lies between 20 and 100 years (depending on the sedimentation rate). The intensity of reflected light is expressed as a color level: red, green, or blue level. The signal thus obtained is expressed in a conventional scale varying between 0 (black) and 255 (red, green, or blue). To reduce the initial length of the data series (close to 16,000 points), the raw color level reflectance data were smoothed by a least squares method and interpolated every $5 \mathrm{~mm}$. The new series contains 
Table 1. Location of Cores Used in This Work and Available Analyses

\begin{tabular}{|c|c|c|c|c|c|}
\hline Name of Core & Latitude & Longitude & Water Depth, $\mathrm{m}$ & Core Length, $\mathrm{cm}$ & Other Analyses \\
\hline SU90-03 & $40^{\circ} 30^{\prime} \mathrm{N}$ & $32^{\circ} 03^{\prime} \mathrm{W}$ & 2475 & 1100 & \\
\hline SU 90-05 & $41^{\circ} 38{ }^{\prime} \mathrm{N}$ & $32^{\circ} 15^{\prime} \mathrm{W}$ & 3285 & 1193 & \\
\hline SU 90-08 & $43^{\circ} 31^{\prime} \mathrm{N}$ & $30^{\circ} 24^{\prime} \mathrm{W}$ & 3080 & 1227 & $\% \mathrm{CaCO}_{3}, \delta^{18} \mathrm{O}$ (N. pachyderma s.) \\
\hline SU90-09 & $43^{\circ} 47^{\prime} \mathrm{N}$ & $31^{\circ} 44^{\prime} \mathrm{W}$ & 3375 & 930 & \\
\hline SU 90-11 & & $40^{\circ} 15^{\prime} \mathrm{W}$ & 3645 & 697 & $\% \mathrm{CaCO}_{3}, \boldsymbol{\delta}^{\prime 8} \mathrm{O}$ (N. pachyderma s.) \\
\hline SU 90-33 & $60^{\circ} 34 \mathrm{~N}$ & $22^{\circ} 05^{\prime} \mathrm{W}$ & 2400 & 1353 & $\% \mathrm{CaCO}_{3}, \delta^{18} \mathrm{O}(G$. bulloides $)$ \\
\hline SU $90-37$ & $55^{\circ} 06^{\prime} \mathrm{N}$ & $20^{\circ} 44^{\prime} \mathrm{W}$ & 2676 & 1250 & \\
\hline SU 90-38 & $54^{\circ} 05^{\prime} \mathrm{N}$ & $21^{\circ} 04^{\prime} \mathrm{W}$ & 2900 & 1142 & \\
\hline SU 90-39 & $52^{\circ} 34^{\prime} \mathrm{N}$ & $21^{\circ} 56^{\prime} \mathrm{W}$ & 3955 & 1295 & $\% \mathrm{CaCO}_{3}, \delta^{18} \mathrm{O}(G$. bulloides $)$ \\
\hline SU $90-42$ & $50^{\circ} 38 \mathrm{~N}$ & $21^{\circ} 44^{\prime} \mathrm{W}$ & 3450 & 1000 & \\
\hline
\end{tabular}

approximately 2500 data points. The difference between raw and smoothed interpolated reflectance curves is smaller than $2 \%$. Thus this process has hardly any effect on the original signal. Lighting conditions are homogeneous from top to bottom for a section of a core and from core to core. There is negligible illumination distortion in the digitized image: the reference curve (a white ruler) has a distortion of about $1 \%$ of the total scale which corresponds to about $3-4 \%$ of the mean signal in the North Atlantic (Figure 2).

\section{Validity of the Reflectance Signal for Paleoclimatic Reconstructions}

In order to document the paleoclimatic validity of this method, we examined the sedimentological parameters of the cores. Marine sediments in the North Atlantic contain three principal components: biogenical carbonate, detrital elements, and, in some areas, volcanic ash [Ruddiman and Glover, 1972; Smythe et al., 1985]. The most important color variations are due to variations in the biogenic carbonate content, which is highly correlated with climatic variations [Crowley, 1983], because their development is seasonal and driven by annual fluctuations of surface water temperature. The Coccolithophoridae (carbonated nannoplankton) and foraminifera are abundant when the water temperature is warm. Consequently, the sediment deposited during those periods is white. During glacial times, the sediment deposited is rich in detrital particles (clay minerals or coarse particles) originating from the continent and transported by bottom currents or ice

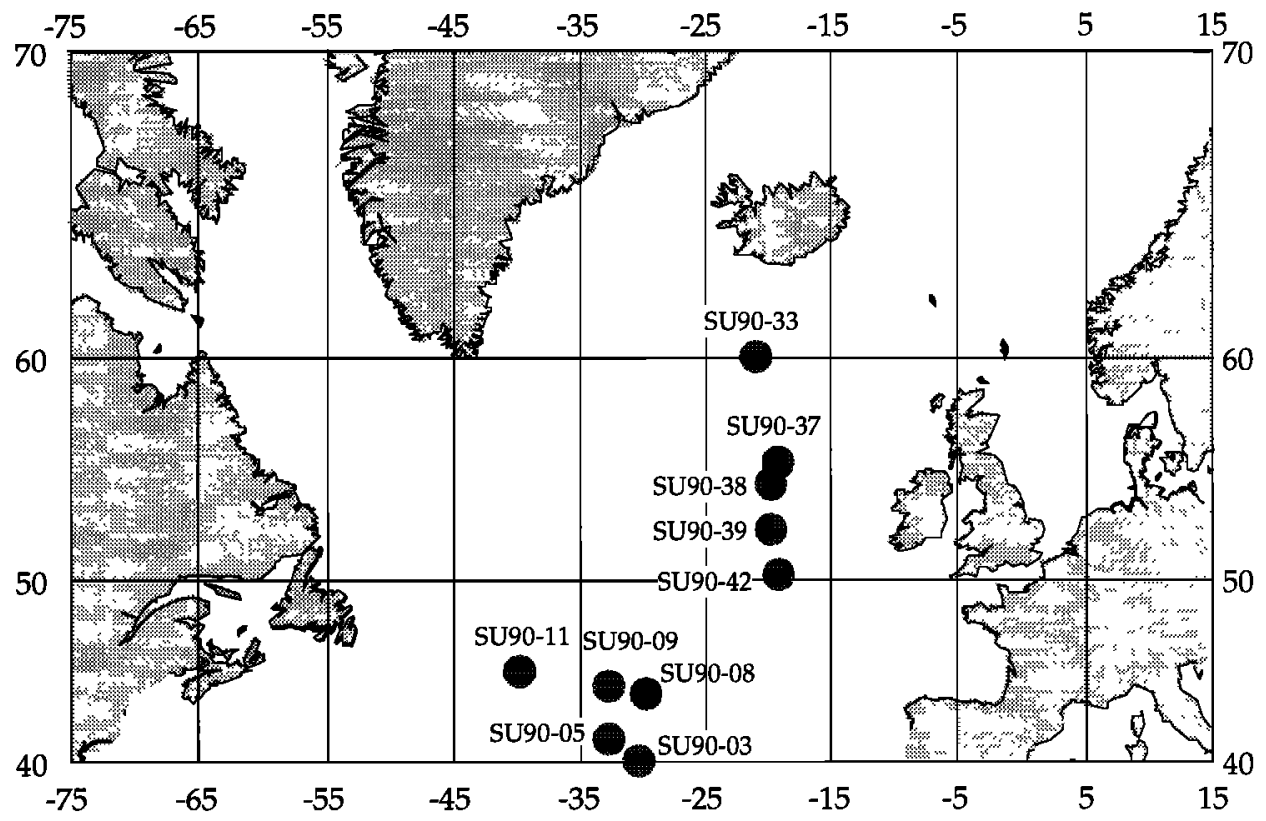

Figure 1. Locations of cores used in this study. 


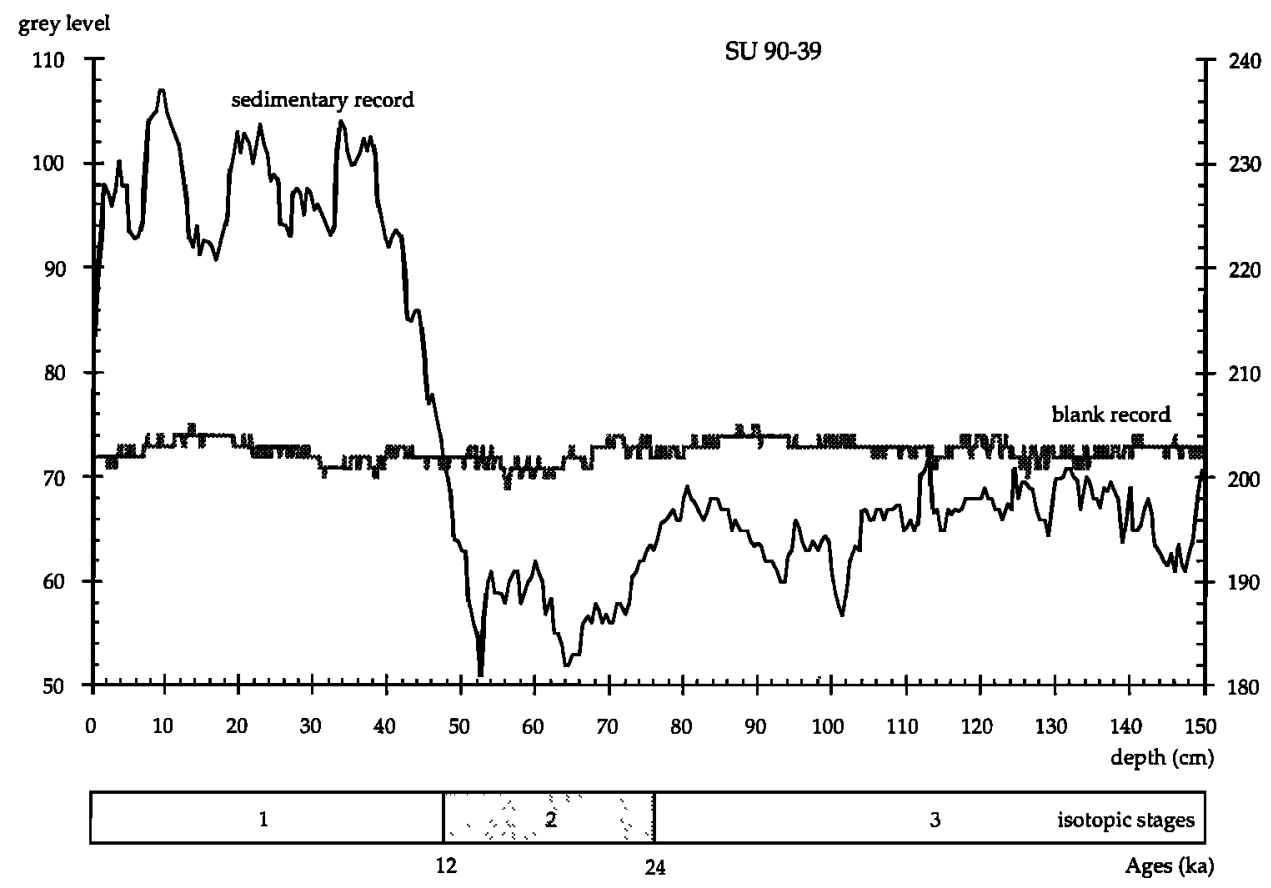

Figure 2. Grey level record of the first section of core SU90-39 compared to the blank record. The thick curve is the blank record with the right scale, and the thin curve is the reflectance profile with the left scale. Isotopic stages are indicated with the transition ages.

rafting. The sediment is therefore dark. Bond et al. [1992a] have shown that the sediment reflectance is well correlated with fluctuations of Neogloboquadrina pachyderma s. (polar foraminifera) and confirm that reflectance is a good indicator of climatic variations. Ash layers are characterized by dark level (about 80 in our conventional scale) which is not related to glacial periods. Around volcanic areas, the climatic signal is altered by the layers left by volcanic eruptions. Thus we did not use cores located around the Azores or Iceland for this study. In the cores we used for this study, the sediment is made up of foraminifera and clays. We selected cores not perturbated by turbiditic processes.

We made regressions between carbonate content (measured by a gasometric technique with a precision of $1 \%$ ) and reflectance on four of the cores (Table 1). The reflectance, carbonate content, and isotope data are shown in Figure 3, and the correlations between each colour channel and the carbonate percentage are shown in Figure 4. The correlation coefficients are 0.864 for the red channel, 0.881 for the green channel, and 0.905 for the blue channel after removing the upper few ten of centimeters of the core which are noticeably offset from the correlation lines. This is due to red coloration of the sediment by iron and manganese oxides. This represents a limit of this method because the most recent part of the sediment is always too dark. The best correlation with $\mathrm{CaCO}_{3}$ is obtained with the green and blue channels. We chose to use the green channel because the blue signal is more affected by the polarizing filter used to decrease direct reflection. In this paper, we will use the term "grey level" to indicate the green channel variations.

The oxygen isotopic composition of planktonic foraminifera expressed as relative $\delta^{18} \mathrm{O}$ (permil versus peedee belemnite (PDB) standard) was measured in the four cores (Table 1 and
Figure 3). This signal depends directly on changes in ice volume, surface water temperature, and salinity [Emiliani, 1955; Shackleton and Opdyke, 1973]. The sampling was made every $5 \mathrm{~cm}$ on average. The species analyzed are Globigerina bulloides and/or $N$. pachyderma left coiling. We compared planktonic isotopic data with sediment reflectance in the same cores. Figure 5 shows this comparison in core SU 90-08. During most of the record, the sedimentary reflectance exhibits the well-known large glacial-interglacial variations. For large timescales, the two signals are in agreement except during rapid events of the last glacial period. The rapid variability during this time is now clearly identified as Heinrich events [Heinrich, 1988; Broecker et al., 1992]. They correspond to the melting of great quantities of icebergs, bringing freshwater (isotopically light) into the surface of the North Atlantic and lithic particles into the sediment. Isotopically, they appear as light peaks of $\delta^{18} \mathrm{O}$, and they are characterized by a globally synchronous dark level in the reflectance data [Bond et al., 1993], but this dark level is interspersed with light shifts perhaps due to the occurence of detrital carbonate levels [Bond et al., 1992b].

In the North Atlantic Ocean, outside the volcanic areas, we can therefore use grey level values as a first-order stratigraphic tool (Figure 6) when the variations in the carbonate contents are large (oscillation areas of the polar and subtropical front).

\section{Comparison Between Grey Level Measurements and Ice Core Records}

Foraminiferal abundance and $\delta^{18} \mathrm{O}$ changes reflect, at least in part, the rapid temperature changes of the air above Greenland during the Dansgaard/Oeschger events [Bond et al., 1993]. 


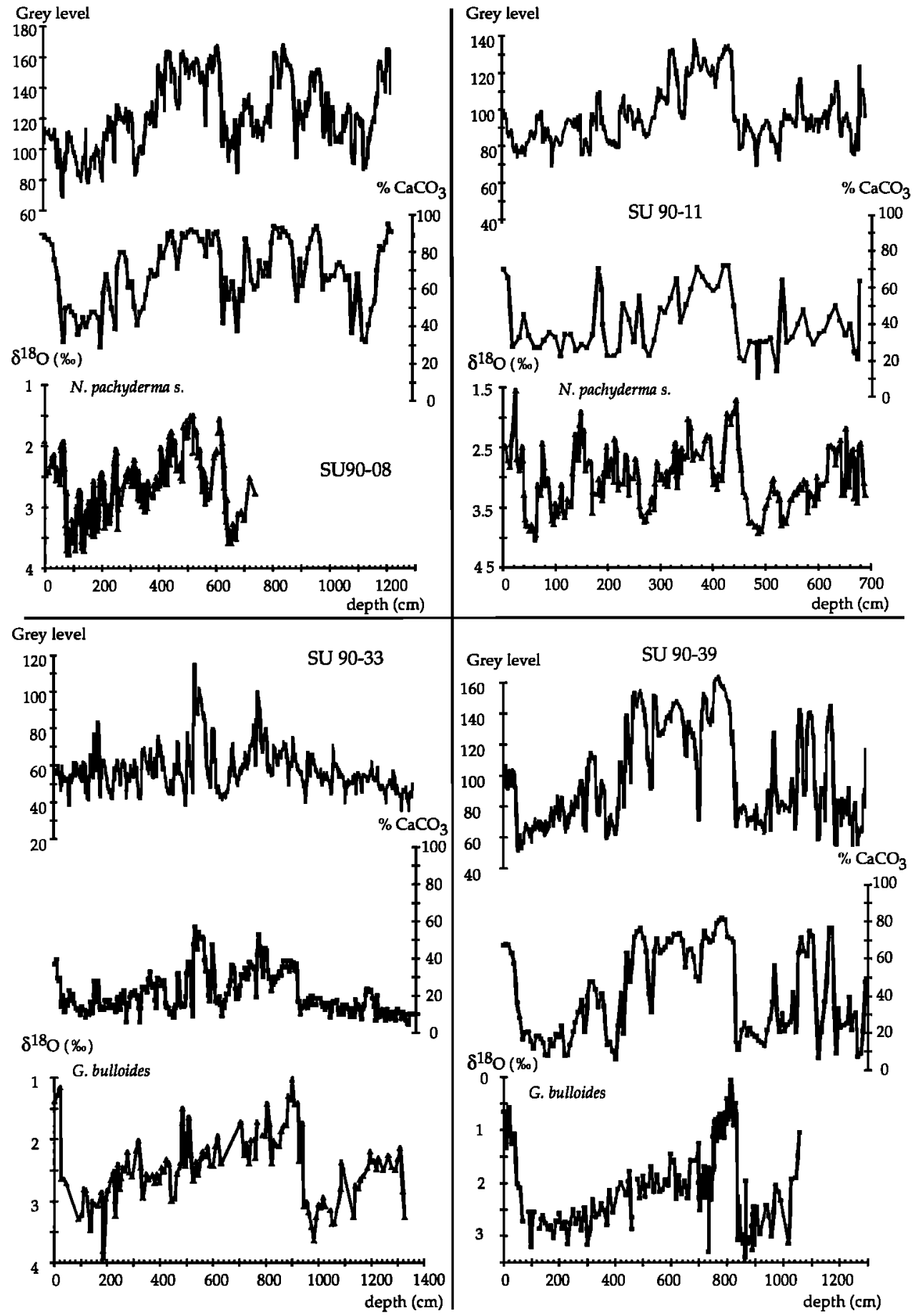

Figure 3. Comparison between grey level, carbonate content, and isotopic $\delta^{18} \mathrm{O}$ on four cores versus depth in the core.

This confirms the strong coupling of the northern Atlantic Ocean with the atmosphere-ice system predicted by various dynamical models [Peltier, 1992]. Because the ice core isotopic records indicate large variability in the $0.5-2 \mathrm{kyr}$ range of duration [Johnsen et al., 1992], we test the validity of the sedimentary reflectance signal by direct comparison between the Greenland ice core (GRIP) and sedimentary records.
Measurements of $\delta^{18} \mathrm{O}$ in the GRIP core provide a proxy for the variations of air temperature over the ice cap with a very high temporal resolution [Dansgaard et al., 1993].

The comparison between the grey level and the GRIP ice core records is shown in Figure 7. The changes between dark and light levels are separated by sharp boundaries and probably do not result from bioturbation mechanisms, which 
Grey level
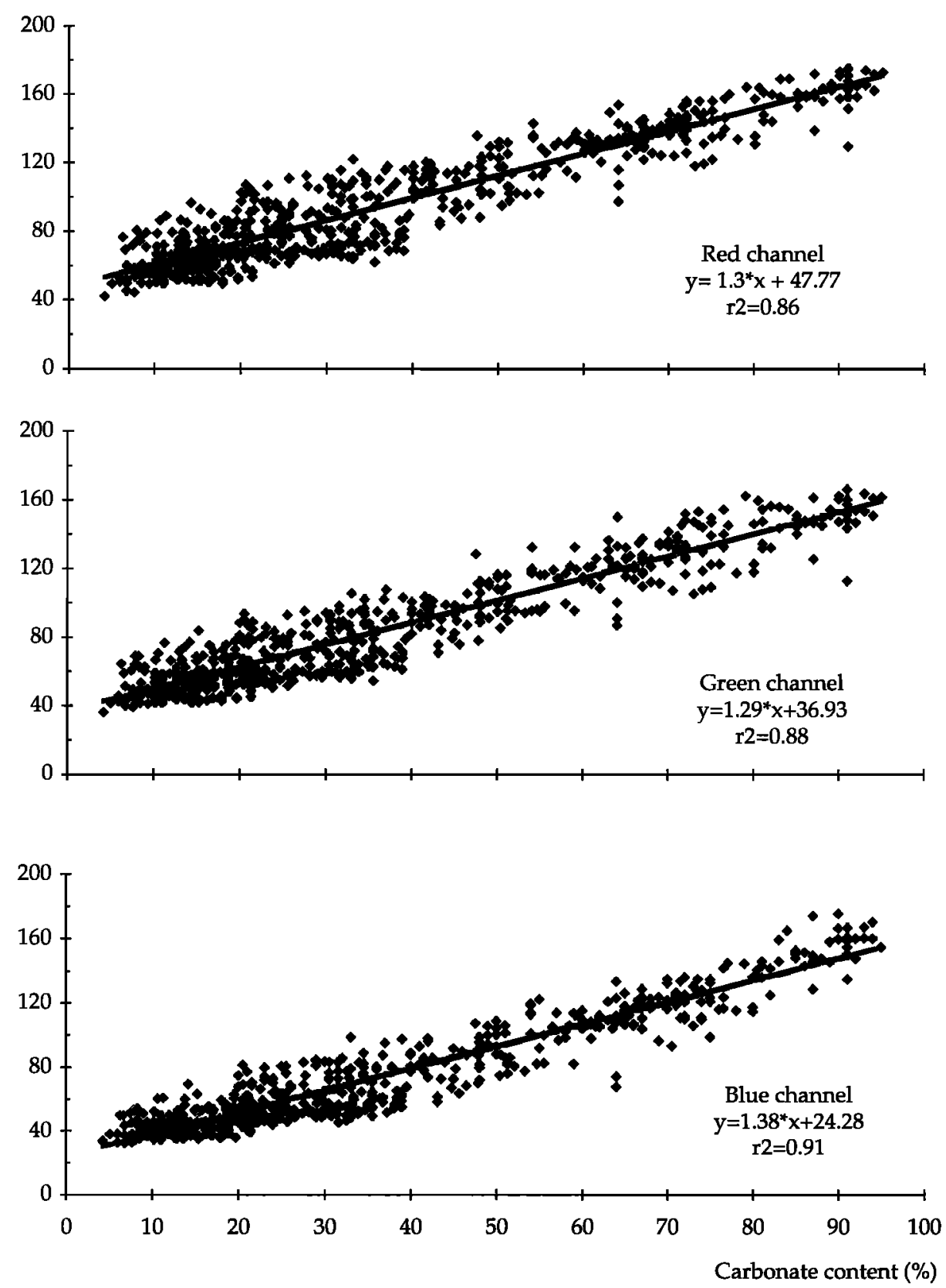

Figure 4. Regression between grey level and $\mathrm{CaCO}_{3}$ measurements in four cores for the red, green, and blue channels. Equations of correlation lines and correlation coefficients are indicated for each color channel. The significance level of this correlation coefficient is $95 \%$.

would, on the contrary, smooth the signal. In addition, in order to remove most of the perturbations from the record, we use an algorithm based on pattern recognition. The digitized color image of the core is, at each depth, about 64 pixels wide, corresponding to the $10-\mathrm{cm}$ width of the core. A rough solution would be to simply choose a "good" profile among these 64 possibilities or to take the mean. Alternatively, the algorithm used here, derived from vocal analyses, tries to find coherent patterns along the core depth and rejects all other pixels. Using the whole width of the core, this filter thus removes most of the local perturbations, such as burrows, provided that they are smaller than the core width. Unlike classical time series filters, this method preserves high frequencies by using most of the information contained in the original two-dimensional color image.

We used the numbering of the interstadial events of the GRIP ice core [GRIP Members, 1993; Dansgaard et al., 1993; Grootes et al., 1993] between 20 and $110 \mathrm{ka}$. The duration of interstadials lies between 0.5 and $2 \mathrm{kyr}$ [Johnsen et al., 1992]. Cores located between $50^{\circ}$ and $60^{\circ} \mathrm{N}$ and $25^{\circ}$ and $15^{\circ} \mathrm{W}$ (SU90-38, SU90-39) show a good correlation with the GRIP record except for the controversial variability during the last 


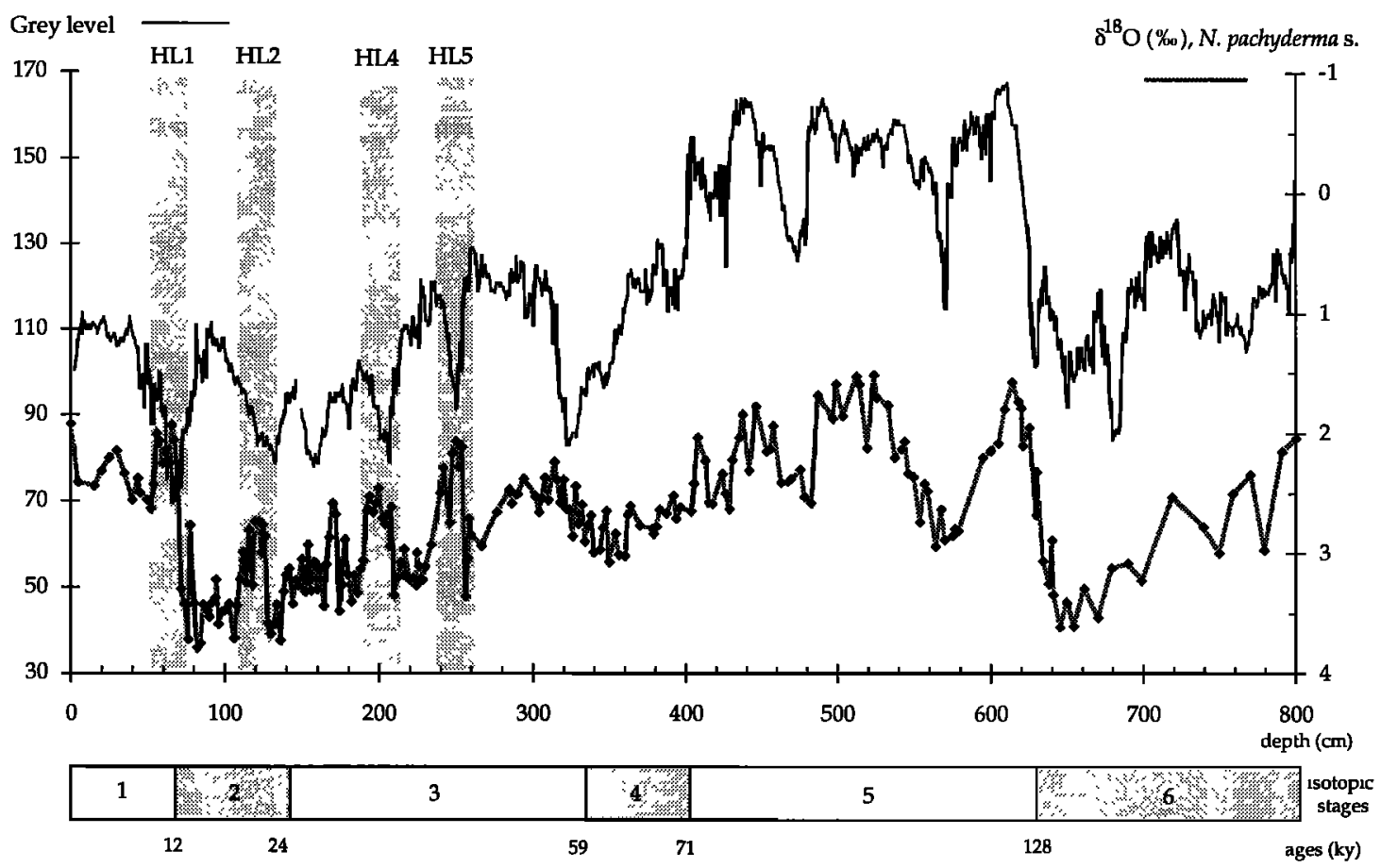

Figure 5. Comparison between isotopic $\delta^{18} \mathrm{O}$ record of $N$. pachyderma s. (diamonds) and the grey level record of core SU90-08. Heinrich layers have been underlined. We can see that the Heinrich layers are characterized by dark levels and light isotopic peaks. This corresponds to the discharge of a great quantity of icebergs which give freshwater melting and dark detrital material.

interglacial [Dansgaard et al., 1993; McManus et al., 1994; Cortijo et al., 1994]. During glacial periods, the DansgaardOeschger events found in the ice may also be clearly observed in marine sediments as small reflectance changes with an amplitude of 10 units or more. These small variations, which last about $1.5-2.0 \mathrm{kyr}$, are indeed very often common to marine sediments and the ice core. During the transition between isotopic stages 5 and 4, all records (marine and ice) have the same pattern. There is an excellent agreement between proxy data for high-latitude temperatures and the marine sediment record. This transition (isotopic stages 5-4) is achieved in several steps, suggesting abrupt changes in atmospheric and thermohaline circulations. These cores are sensitive to Gulf Stream variations and to the associated heat transport. These results are in agreement with those of Keigwin and Jones [1994].

On the other hand, the cores located between $35^{\circ}$ and $45^{\circ} \mathrm{N}$ and $30^{\circ}$ and $40^{\circ} \mathrm{W}$ (SU90-08, SU90-05) do not show as good a correlation with the Greenland record for rapid variability, although we easily recognize the successions of glacialinterglacial periods. This can be due to some smoothing effect of the climatic system which weakens the effects of the events initiated in the North Atlantic as they are transported toward the south. Another possibility is that the rapid oscillations are due to Gulf Stream variations which are well marked only in area of climatic front oscillations (polar or subpolar front).

\section{Variability of the Grey Level Records in the Frequency Domain}

Several sediment core studies have identified significant high frequencies in paleoclimate proxy data [Pisias et al., 1973; Pestiaux et al., 1988]. Due to their very fine temporal resolution, reflectance records are appropriate to test the periodicities of the suborbital timescale. We chose two specific cores to perform several detailed spectral analyses. Each of them is representative of an area of the North Atlantic (Table 2). Core SU90-08 (Figure 1) is located in the southern boundary of the polar front oscillation [Climate: Long-Range Investigation, Mapping, and Prediction (CLIMAP) Project Members, 1984]. Core SU90-39 (Figure 1) is located in the northern boundary of this area (area of maximum of oscillation).

\section{Chronology}

We developed a timescale for each site based on accelerator mass spectrometry (AMS) ${ }^{14} \mathrm{C}$ dates (until $30 \mathrm{ka}$ ), benthic and planktonic $\delta^{18} \mathrm{O}$, and the Spectral Mapping (SPECMAP) stack [Pisias et al., 1984]. In core SU90-08, the sampling resolution of benthic and planktonic foraminifera signals is $2 \mathrm{~cm}$ for $0-128$ kyr and $5 \mathrm{~cm}$ for 128-285 kyr (for planctonic foraminifera only). In the uppermost portion of the record, the ${ }^{14} \mathrm{C}$ available data were included. The SPECMAP chronology was applied using 


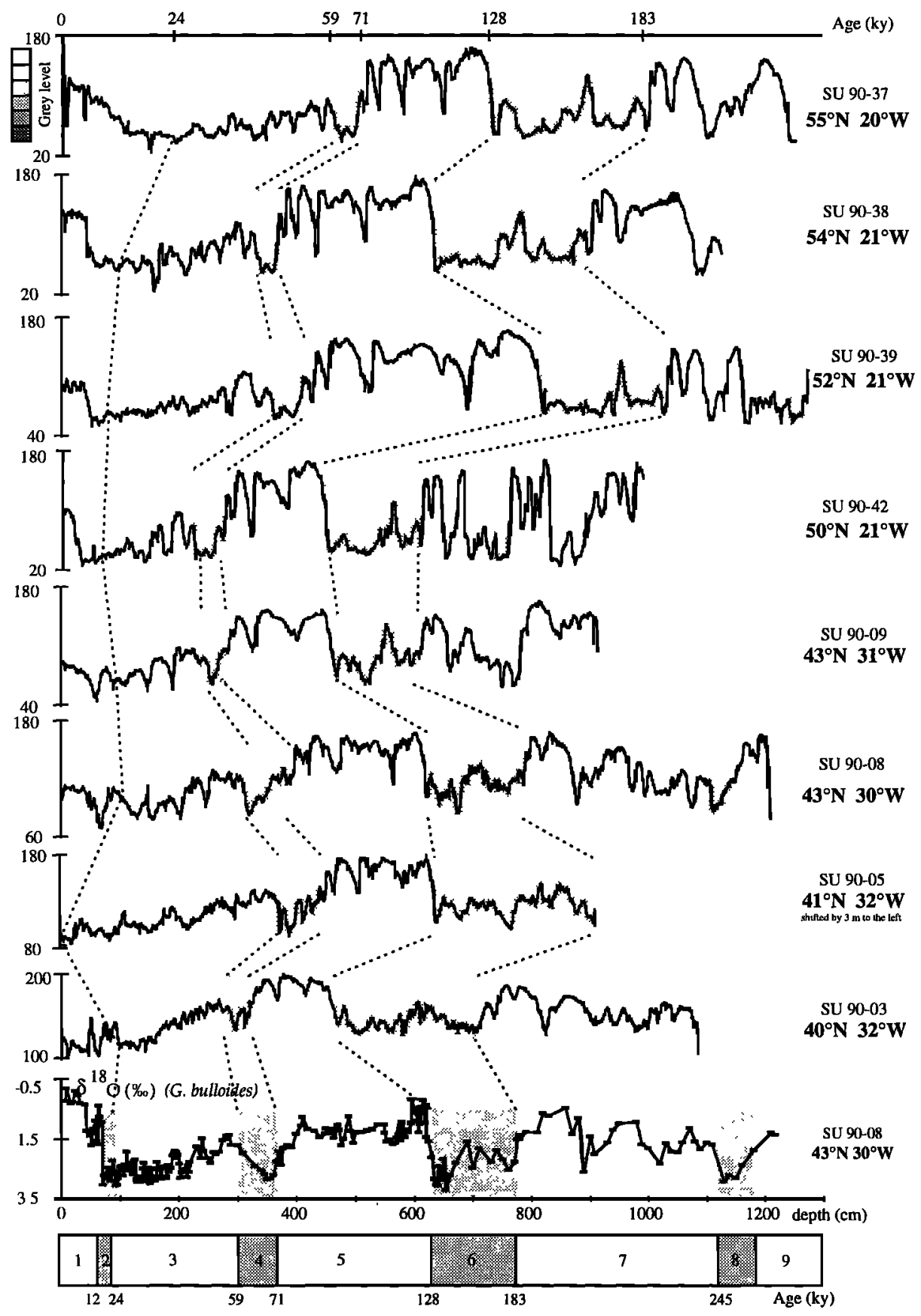

Figure 6. Correlation between several cores in the North Atlantic Ocean and the $\delta^{18} \mathrm{O}$ record of Globigerina bulloides in core SU90-08 (age scale at bottom). Glacial periods are dashed. The age scale at the top corresponds to core SU90-37.

the software AnalySeries [Paillard, 1995a]. Between the stratigraphic correlation levels, the sedimentation rate is assumed to be constant and a linear interpolation was applied. In core SU90-39, the sampling resolution is more irregular, varying between $2 \mathrm{~cm}$ and $10 \mathrm{~cm}$. The SPECMAP chronology was applied in this case too. The age-depth relation for the two cores is shown in Figure 8. We make no claim that our stratigraphies are the most accurate, but they are built using all available classical stratigraphic signals. The theoretical sampling lies between 20 and 50 years. The corresponding mean Nyquist period (the theoretically shortest period) and the mean sedimentation rate for each core are indicated in Table 2. 

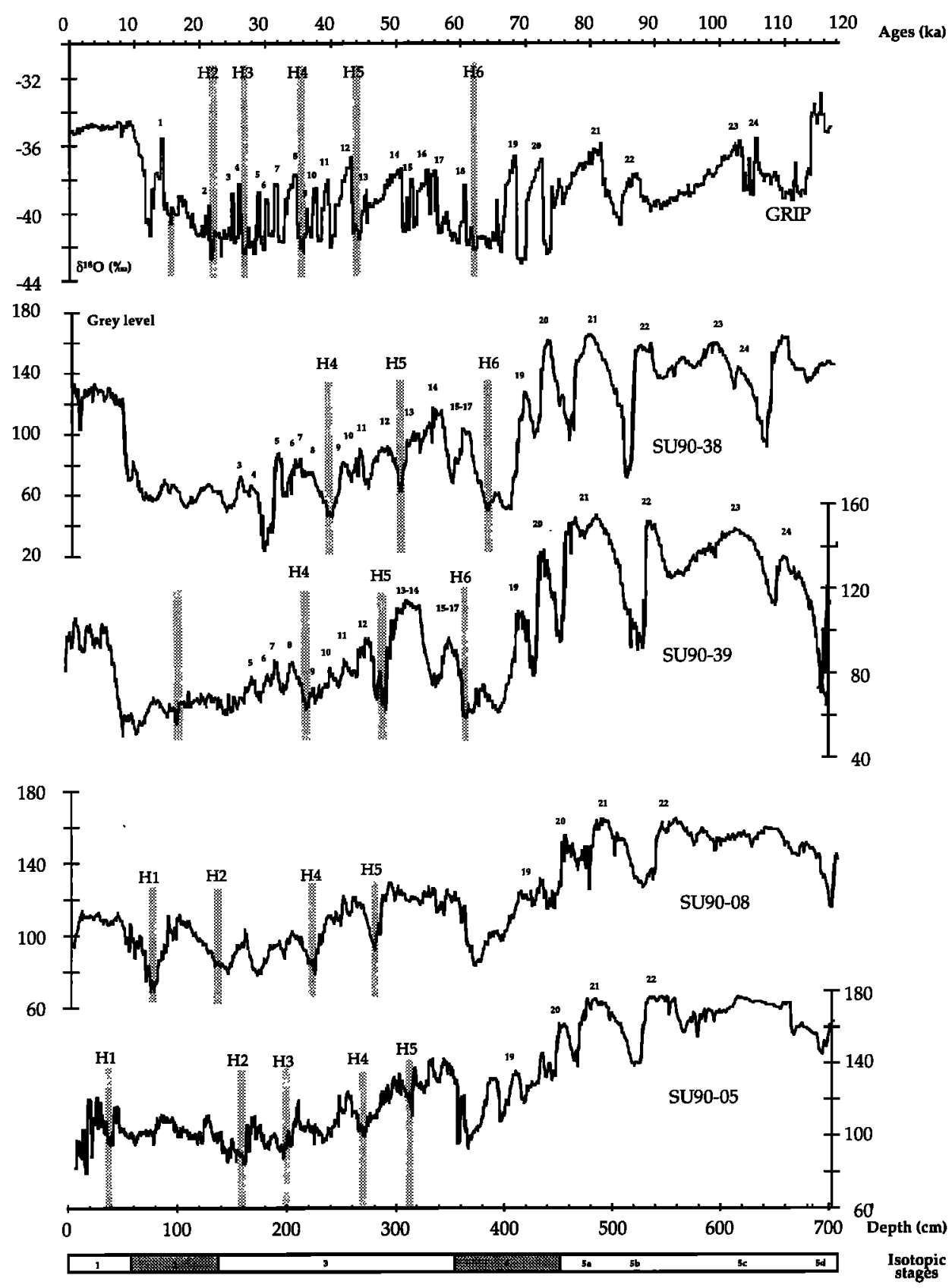

Figure 7. Correlation between the GRIP (Greenland Ice core Project) record versus age [Dansgaard et al., 1993] and the sedimentary grey level of the North Atlantic cores. These grey level records are obtained using a filter which removes all pertubations in the stratigraphy. All North Atlantic cores were put on the same depth scale. The numbering corresponds to the interstadial events of the ice and has been used for marine cores as well.

However, the sedimentation rate is not constant along a given core; this implies a variable time step and a variable Nyquist period.

\section{Spectral Methods}

The study of the orbital components and the high-frequency variability on those time series was made with several spectral methods. Each of them examines a particular feature in a time series, and combining those different spectral analyses permits avoiding spurious results and thus enhances the confidence of our estimates. The techniques used are multitaper method and wavelet transform. We also use singular spectrum analysis in order to separate the signal and the noise. Then we can analyze the high-frequency variations.

Multitaper method. The purpose of this nonparametric spectral method [Thomson, 1982] is to compute a set of independent and significant estimates of the power spectrum, in order to obtain a better and more reliable estimate than with 
Table 2. Sedimentation Rate and Nyquist Frequency of Cores Used in the Spectral Analysis

\begin{tabular}{lllll}
\hline Name of Core & Mean Sedimentation Rate, cm/kyr & Age at Bottom, kyr & Time Sampling, years & Nyquist Period, years \\
\hline SU 90-08 & 3.8 & 303 & 34 & 68 \\
SU 90-39 & 5.2 & 244 & 25 & 50 \\
\hline
\end{tabular}

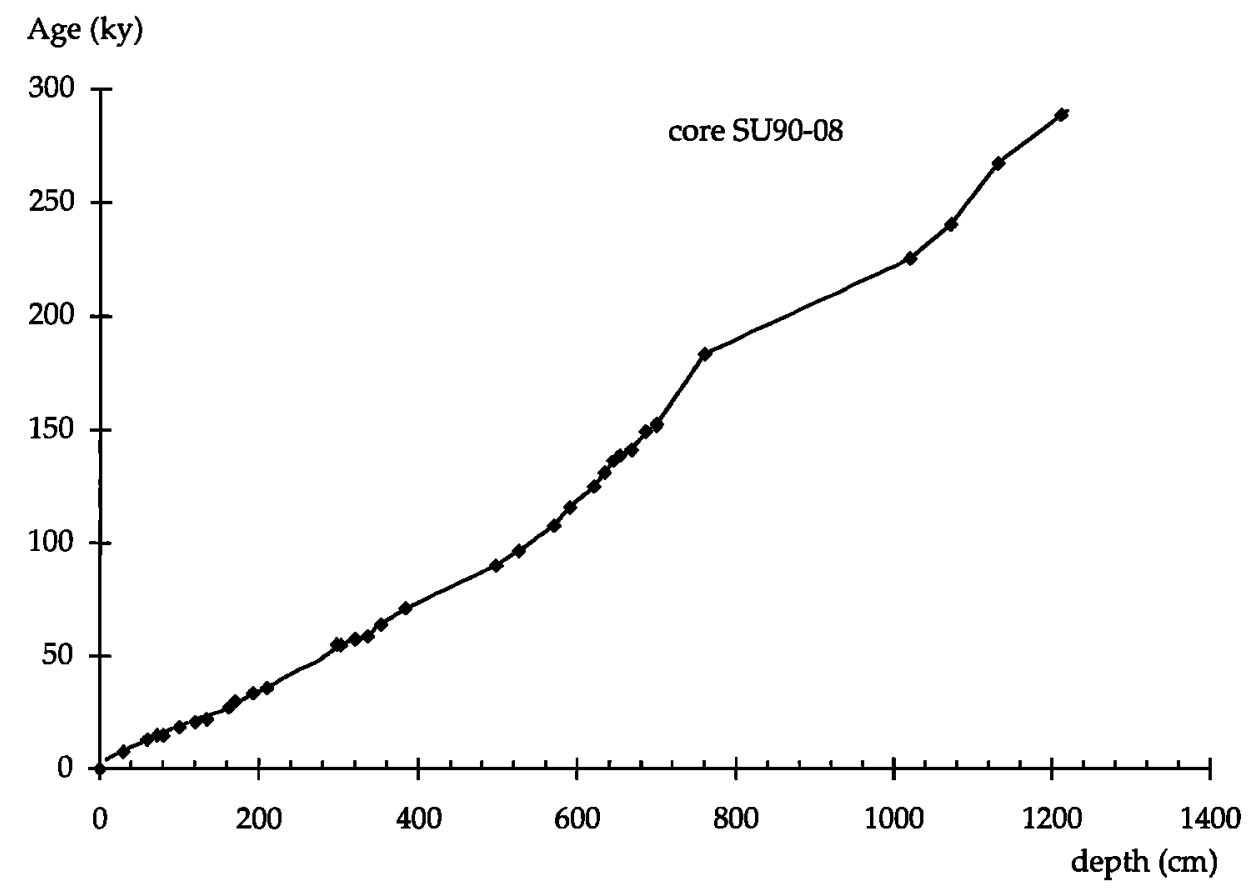

Age (ky)

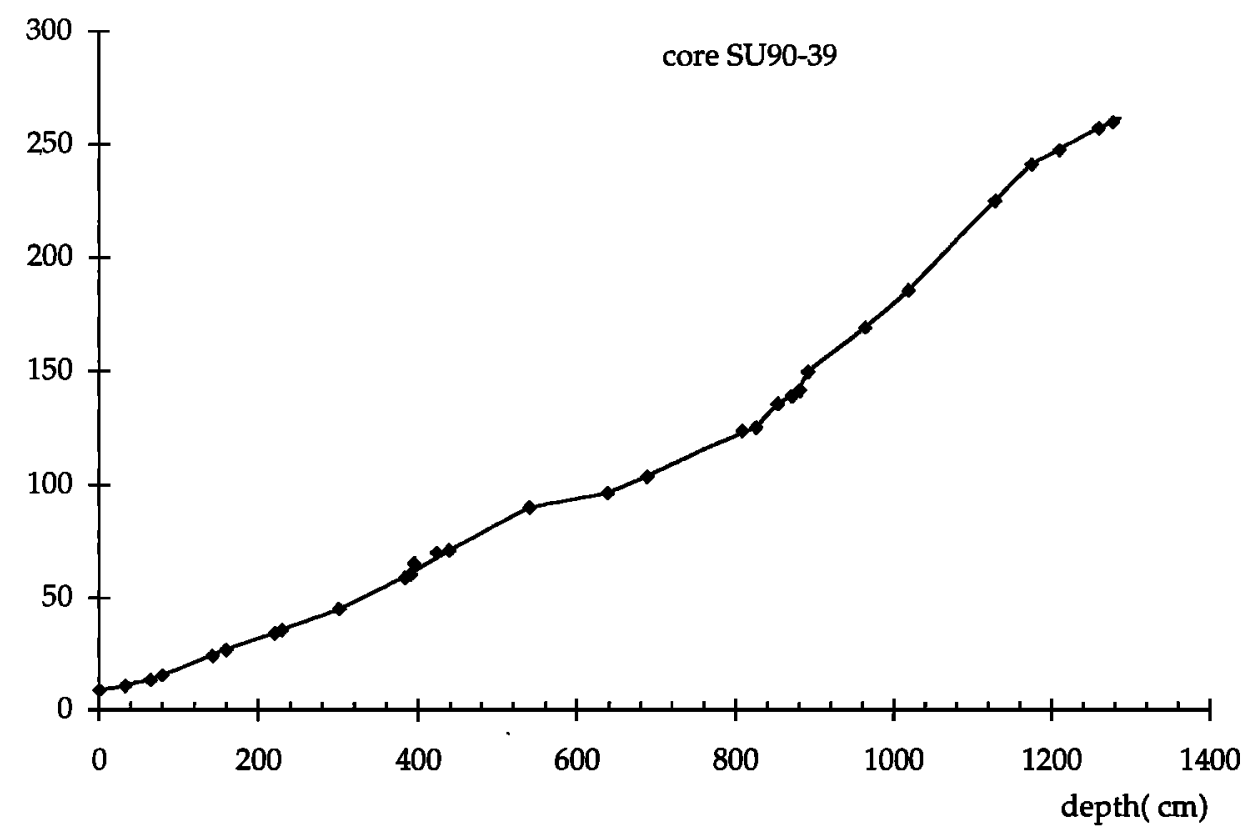

Figure 8. Age-depth relation for the two studied cores: (top) core SU90-08 and (bottom) core SU90-39. The sedimentation rate is relatively regular in the two cores except during stage 6 (around $160 \mathrm{kyr}$ ) of core SU9008 . 

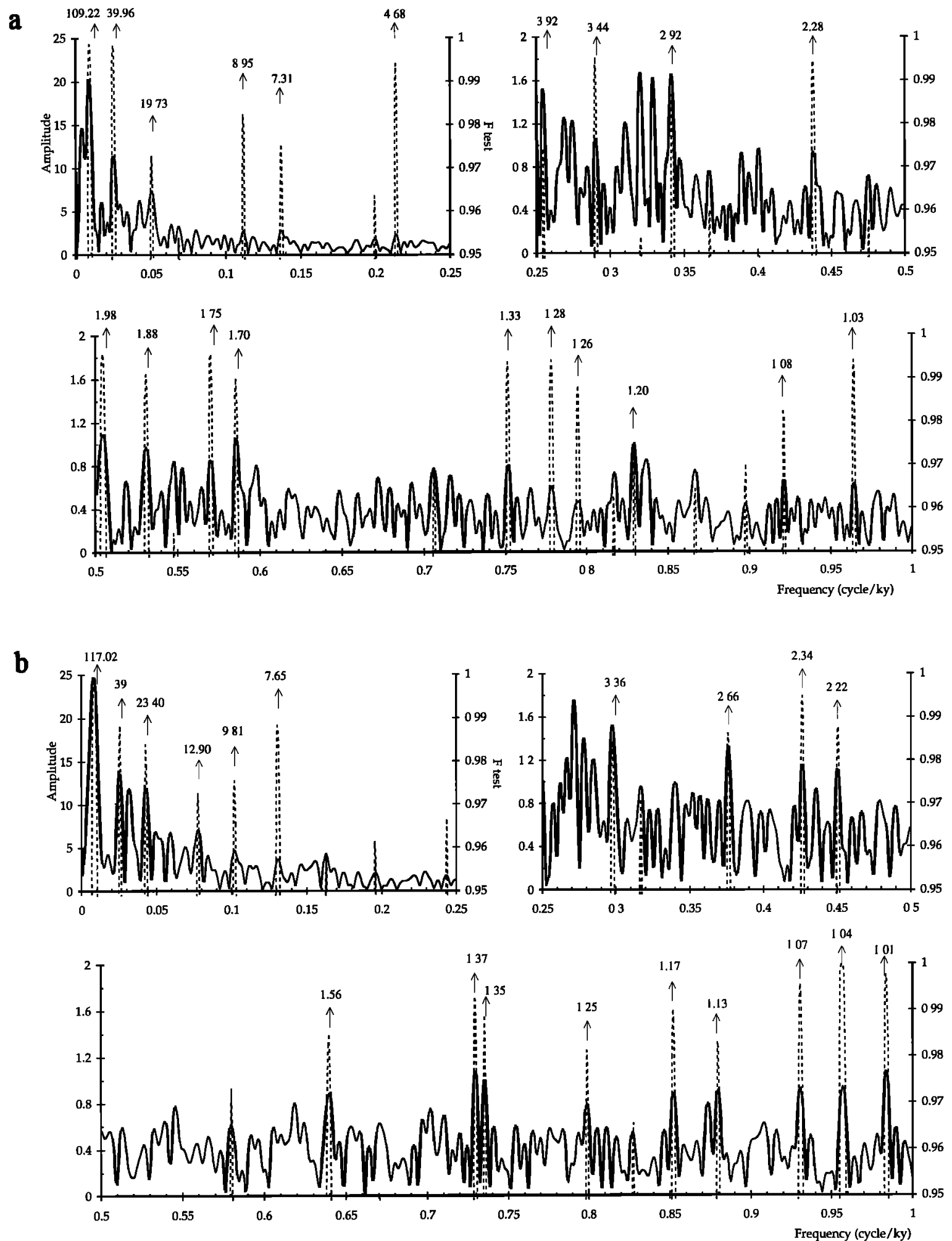

Figure 9. MTM (multitaper method) spectra of raw grey level on cores (a) SU90-08 and (b) SU90-39. The solid line represents the line amplitudes, and the dotted line represents the $F$ test of estimate confidence. For a better representation, the frequency range $0-1$ has been divided into three panels. The significative periodicities have been indicated. 
single-taper methods given a finite and possibly short time series. A set of optimal tapers is calculated so that this approach to spectral estimation is less heuristic than traditional (e.g., Blackman-Tukey) techniques. The tapers are calculated to optimize the spectral leakage due (to the data finiteness) outside a prescribed bandwidth $W$, for a periodic signal [Thomson, 1982]. The number of relevant tapers is then proportional to the bandwidth [Slepian, 1978], so that a tradeoff between resolution (small $W$ ) and confidence (large number of tapers) has to be found, by trial and error or other heuristic criteria [Thomson, 1982].

Thus, with a set of $K$ tapers with a given bandwidth $W, K$ independent spectral estimates can be computed for a time series $X$, from the product of $X$ and each taper. An average over these spectra gives a multitaper spectral estimate which possesses good statistical properties [Thomson, 1982].

Multitaper methods (MTM hereafter) are also useful to compute the harmonic analysis of a time series, i.e., to determine the amplitude and frequency of its line components. This is done through a least squares regression in the frequency domain. Under white noise hypotheses, the amplitude and line frequency estimates are unbiased [Lindberg, 1986], and they are robust to such hypotheses when a red noise is used
[Vautard et al., 1992]. The harmonic analysis estimates provide a statistical test (Fisher or $F$ test) for the amplitude spectrum. High values of this test allow rejection of the null hypothesis of a nonperiodic component at some frequency.

One of the main assumptions of this technique of harmonic analysis is that the signal must yield periodic and separated components. If not, a continuous spectrum (in the case of a colored noise or a chaotic system) will be broken down to spurious lines with arbitrary frequencies and possibly high $\mathrm{F}$ values. This is a danger of the method, which can be partially avoided if the raw power spectrum is computed and hints for lines are detected; it is also very important to vary the bandwidth parameter $W$ and the number of tapers to ensure the stability of the frequency and module estimates.

Singular Spectrum Analysis. Singular spectrum analysis (SSA hereafter) takes its roots in digital signal processing and nonlinear dynamics [Broomhead and King, 1986; Vautard and Ghil, 1989]. It is designed to extract information from short and noisy time series, without prior knowledge of the dynamics of the underlying system that generated the series. The starting point of the method is to embed a time series of observables $X(t), t=1 \ldots N$ in a vector space of dimension $M$. The embedding procedure consists of constructing a sequence
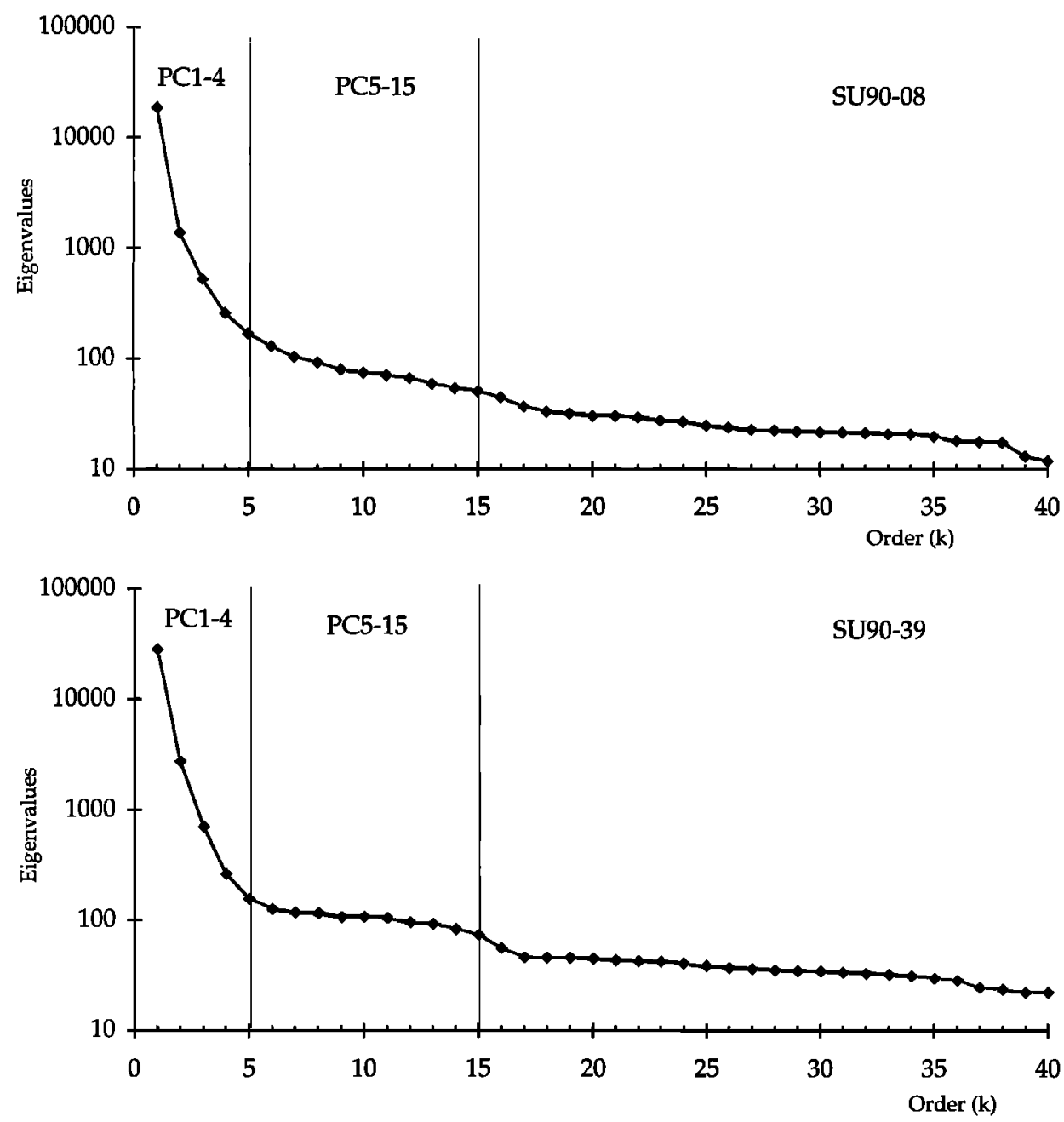

Figure 10. Singular spectrum analysis (SSA) eigenvalues of grey level of cores SU90-08 and SU90-39. The vertical lines divide the different zones of the spectra between principal components (PC) 1 to 4 and PC5-15. 
$\Xi$ of $M$-dimensional vectors of delayed coordinates from the time series $X$

$$
\Xi(t)=(X(t), X(t+1), \ldots, X(t+M-1)), t=1 \ldots N-M+1 .
$$

If the system dimension $d$ is relatively small $(d<3)$, such a procedure can give a stuniling reconstruction of the system attractor [Gershenfeld, 1988]. On the other hand, if $d$ is larger than four, a raw application of this technique fills any twodimensional projection in a dense way so that no visual information can be retrieved. SSA allows unravelling of the information entangled in the delayed-coordinate phase space by decomposing the sequence of vectors $\Xi$ into elementary oscillation patterns. Hence this method generates dataadaptative filters for the separation of the time series into independent components, like trend, deterministic oscillations, and noise.

The directions of extension of the sequence of augmented vectors $\Xi(t)$ are determined. An $M x M$ covariance matrix of $X, C_{X}$, is computed, as well as its eigen elements $\left(\lambda_{k}\right.$, $\rho k), k=1, \ldots, M$

$$
C_{X} \rho_{k}=\lambda_{k} \rho_{k}
$$

The eigenvalues $\lambda_{k}$ give the extension of the time series in the direction given by the (orthogonal) eigenvectors $\rho_{k}$ : the $\lambda_{k}$ are associated to the variance of the oscillating pattern detected by the $\rho_{k}$. Therefore plots of the sorted eigenvalues allow discrimination between high variance oscillations with steep slope and noise characterized by low values and a flat floor [Vautard and Ghil, 1989]. Projections of the time series onto the eigenvectors yield the principal components (PCs) $a_{k}$

$$
a_{k}(t)=\sum_{i=1}^{M} X(t+i) \rho_{k}(i)
$$
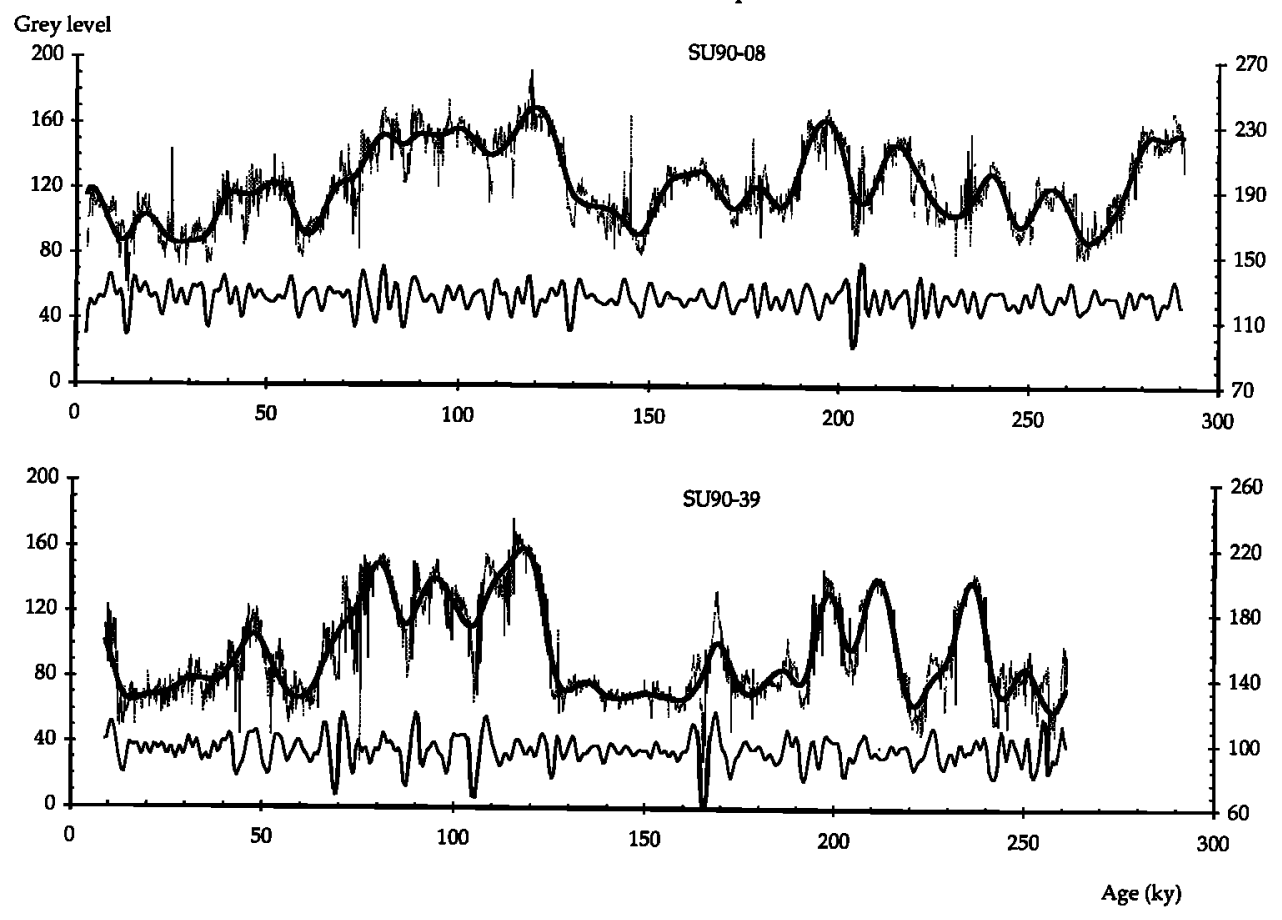

Figure 11. Raw grey level of cores (top) SU90-08 and (bottom) SU90-39 with the corresponding reconstructions. For the two cores, the raw grey level is the thin dotted curve, PC1-4 is the solid thick curve (both with left scale), and the thin solid curve is the PC5-15 (with right scale).

A time series associated to a single or several eigenvectors $\rho_{k}$ can be reconstructed by combining the associated principal components

$$
r_{\Lambda}(t)=\frac{1}{M_{t}} \sum_{k \in \Lambda} \sum_{i=1}^{M} a_{k}(t-i) \rho_{k}(i),
$$

where $\Lambda$ is the set of empirical orthogonal functions (EOFs) on which the reconstruction is based and $M_{t}$ is a normalization factor [Vautard et al., 1992]. This reconstruction process preserves the phase of the time series, so that $X$ and $r_{\Lambda}$ can be superimposed on the same timescale. Once the noise and trend components are identified by SSA decomposition, a clean signal can be reconstructed and analyzed, pattern-wise or with other mathematical tools.

Wavelets. Most observational signals are not stationary and contain transient components which excite a wide range of frequency in a limited amount of time. This motivates the use of time-frequency representations and wavelet transforms. Applications of wavelet transforms have been extensively reviewed by Grossmann et al. [1989] and Farge [1992].

The main property of a wavelet decomposition is that the analyzing functions (the wavelet functions) are localized both in time and frequency, i.e., they oscillate in a finite amount of time and vanish, as well as their Fourier transform. On the opposite, the sine and cosine functions (of Fourier transforms) are perfectly localized in frequency but oscillate endlessly in time. Hence a classic Fourier analysis spreads the singularities of a time series over the entire power spectrum, creating spurious peaks or concealing real ones, unless an ad hoc timefrequency analysis is performed, such as by Yiou et al. [1991] or Birchfield and Ghil [1993]. As a wavelet decomposition only uses dilatations and translations of a unique function, it is optimal in the sense of the so-called time-frequency SU90-08 
uncertainty principle [Farge, 1992], in that the correlation between duration and average frequency is respected.

A wavelet analysis decomposes a time series into scale components, hence allowing a discrimination between oscillations occurring at fast (time) scales and others at slow scales. More precisely, for some signal $X$ and a given wavelet function $\psi$, the $\psi$ wavelet transform of $X$, at a scale $a$ and a time $b$, is given by

$$
W_{\psi} X(a, b)=\frac{1}{\sqrt{ } a} \int_{-\infty}^{\infty} \psi\left(\frac{t-b}{a}\right) X(t) d t .
$$

This integral expresses an analysis of $X$, localized around $b$ and scaled by the parameter $a$. The wavelet decomposition is represented in a dilatation (scale)-translation (time) plane. A logarithmic scale axis allows for a better resolution of smallscale components, i.e., high frequencies.

In the case of a purely monochromatic signal $X(t)=A \exp ($ $\omega_{0} t$ ), the wavelet transform is

$$
W_{\psi} X(a, b)=A \frac{a}{2 \pi} \widehat{\psi}\left(a \omega_{1}\right) e^{i \omega_{0} h}
$$

where $\hat{\psi}$ is the Fourier transform of $\psi$. From this relation, the modulus of $W_{\psi} X$ does not depend on the translation time $b$, and the phase of the wavelet transform at a scale $a$ directly gives $\omega_{0}$. This means that in such a representation, the wavelet transform of a purely periodic signal is a ridge at a constant scale [Farge, 1992].

In this paper, we use the complex Morlet wavelet

$$
\psi(t)=\exp \left(2 i \mathrm{p} \omega_{0} t\right) \exp \left(-t^{2} / 2\right)+\text { negligible correction terms, }
$$

i.e., a complex exponential modulated by a Gaussian function. We truncated the sides of the wavelet transforms to avoid spurious side effects.

\section{Results of Spectral Analyses and Discussion}

In the two cores (SU90-08 and SU90-39), the grey level records are investigated with MTM harmonic analysis. MTM results are shown in Figures 9a (core SU90-08) and 9b (core SU90-39). In the following discussion, we will only consider peaks with confidence tests (normalized statistical $F$ test) greater than 0.97 .

Frequencies associated with orbital parameters (precession and obliquity) are well defined in both cores with high values of amplitude (between 8 and 25). High frequencies have much smaller values of amplitude. Some of these periodicities were detected in other works: Hagelberg et al. [1994] and Yiou et al. [1994] have observed "submilankovitch" periodicities between 10 and $12 \mathrm{kyr}$. They correspond to variability which can be attributed to internal climatic system, nonlinearly coupled to precession forcing [Hagelberg et al., 1994]. The periodicities between $1 / 5$ and $1 / 8$ cycle per kyr exist in the two cores and could be related to Heinrich events. They have also been found in ice core records [Yiou et al., 1995], and it can be speculated that these oscillations are symptomatic of the succession of rapid oscillations during the glacial period. SSA analyses allow us to determine which is the part of the noise in the grey level signal. Singular spectra are obtained by taking an embedding dimension of 40 (time sampling is $0.5 \mathrm{kyr}$ and the window size represents $20 \mathrm{kyr}$ ) and are presented in Figure 10. In both cores, the spectra can be separated in three disctinct regions: the first part (PC1-4) with a steep slope dominated by the large glacial-interglacial variations (linked to orbital frequencies), an intermediate region with a more gentle slope (PC5-15) which contains high-frequency variations, and the final noisy region. The reconstruction of the principal components is shown in Figure 11. Spectral analyses made on these reconstructions show that the frequencies detected by the MTM method are real and not linked to noise.

Because of its temporal resolution, sedimentary reflectance provides detailed information in the higher frequencies. Between $1 / 4$ and $1 / 1$ cycle per kyr, both cores present significative periodicities although they are not exactly the same. These results confirm that marine sediments can record high-frequency climatic oscillations.

We could identify some oscillations with MTM analyses, but this method does not give information about the stationariness of the features we find. In order to study how those different periodicities evolve in time, we use a wavelet analysis on both cores. However, the low and high frequencies determined by MTM analysis in the two cores are not stationary, and no perfectly stationary components are detected. This is also the case for ice core records [Yiou et al., 1995] which do not show any stationary frequency.

However, the wavelet representation of core SU90-39 shows many similarities with the ones obtained for the GRIP record, although it is relatively different from the ones obtained in core SU90-08 (Figure 12). This is in agreement with the qualitative observation made by direct comparison between the SU90-39 grey level and the GRIP $\delta^{18} \mathrm{O}$ record.

The two cores show nonstationary suborbital periodicities between 5 and $1 \mathrm{kyr}$. Several simple climatic models [Welander, 1982], and also some more complex models, like two-dimensional ones [Hovine, 1993], have shown oscillations. The conceptual salt oscillator climate model [Broecker et al., 1990; Birchfield and Broecker, 1990] fluctuates between an "on" (the northern hemisphere is relatively warm because of the large transport of heat to high latitudes) and "off" mode (the northern hemisphere is cold, a consequence of the greatly reduced thermohaline circulation) with a period of the order of $1 \mathrm{kyr}$. But those oscillations are not spontaneous; they are forced by external freshwater input. This model emphasizes the role of salt fluxes and their control of density gradient. Other simple models present spontaneous oscillations in the millennium timescale because of ice-sheet oscillations [Birchfield et al., 1994; Paillard, 1995b]. Hovine [1993] shows in a two-dimensional model that the salinity fluxes in high latitudes of the northern hemisphere play a determining role. He finds oscillations with a periodicity of 1.5 kyr. These model results are in accordance with the results of our grey level spectral analyses.

\section{Conclusion}

Sediment records in the North Atlantic contain exceptional archives of paleoclimates. The comparison between grey level records of marine cores and isotopic ice core records has revealed that rapid climatic variability can be distributed in two areas. 
a

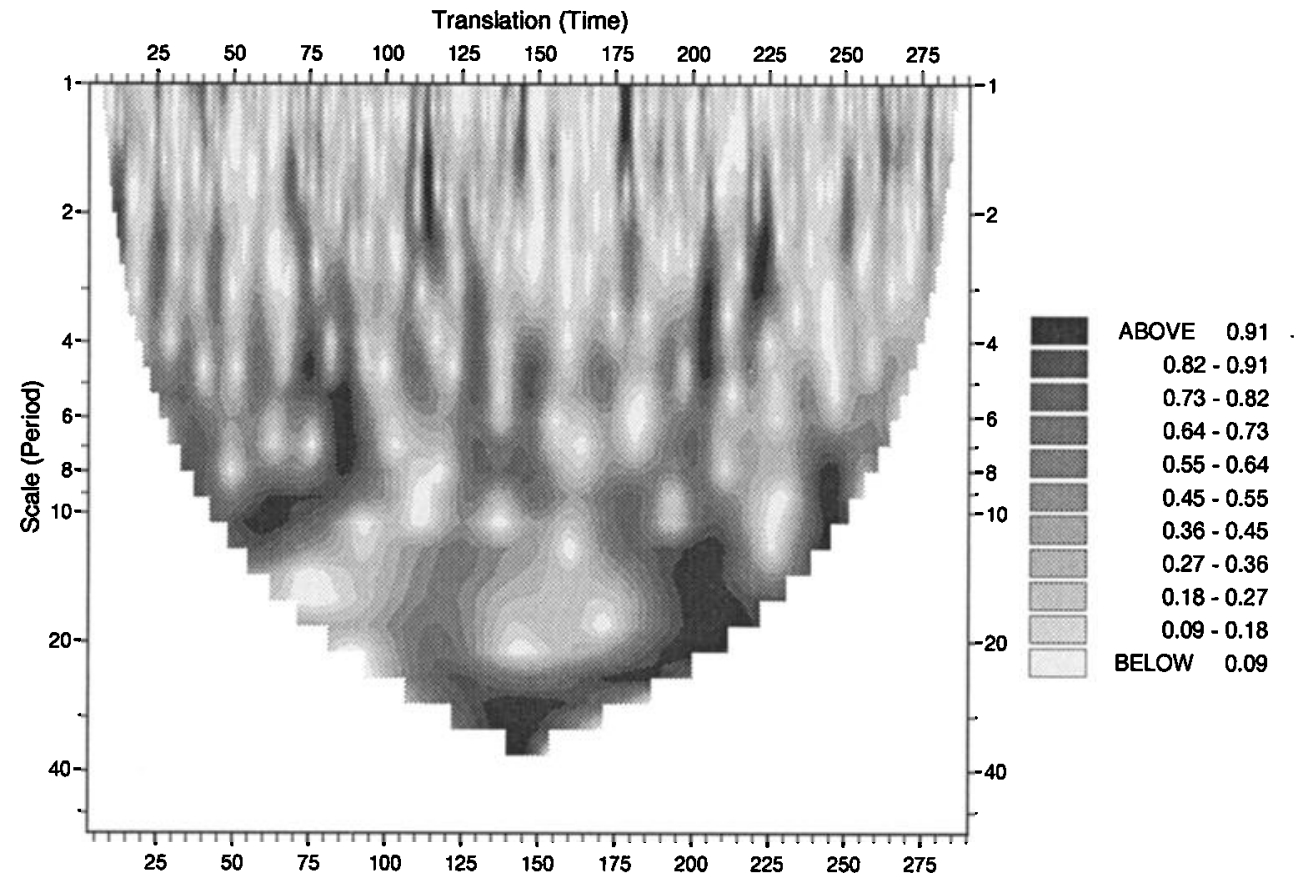

b

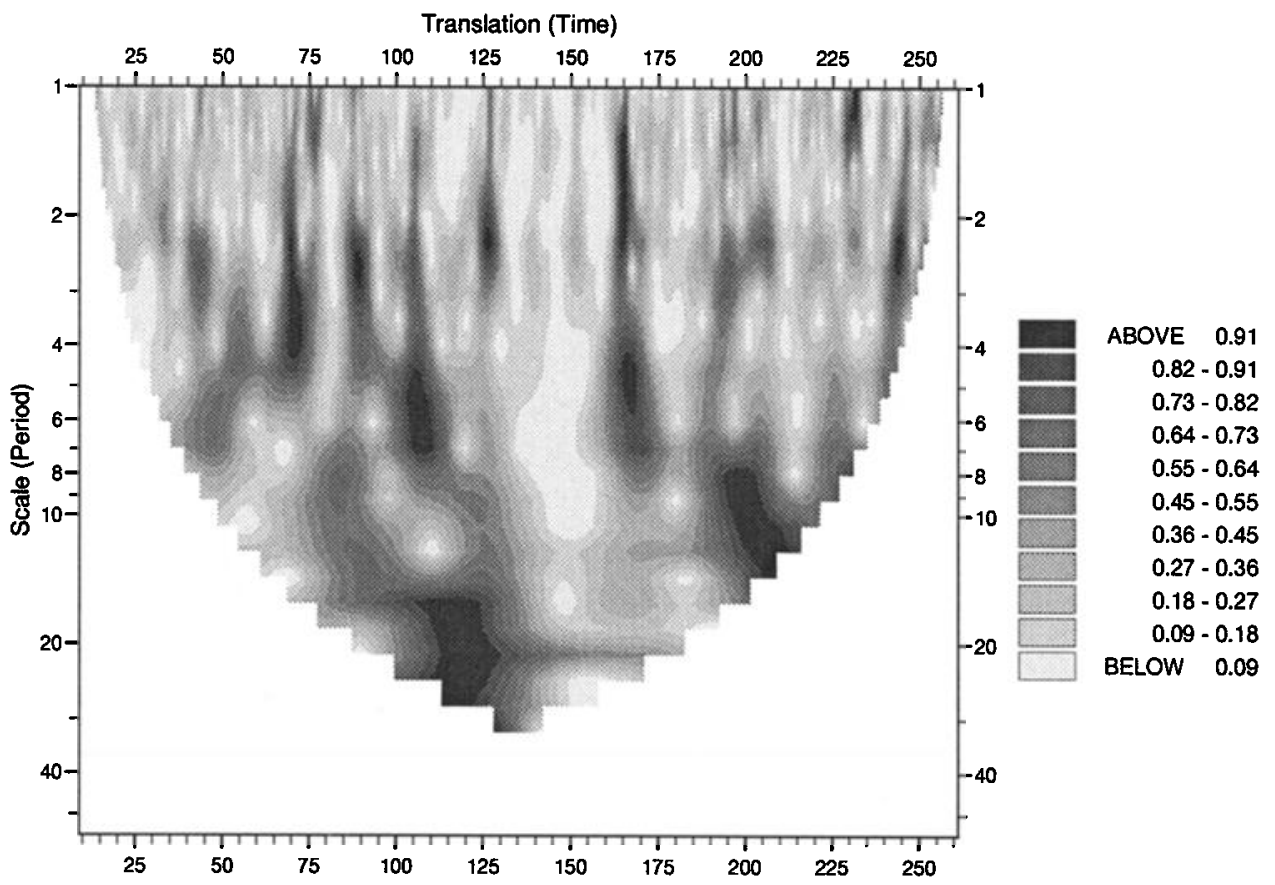

Figure 12. Modulus plots of the wavelet analysis of raw grey level of cores (a) SU90-08 and (b) SU90-39. The horizontal axes represent time translations, and the vertical axes represent scale dilatations (analogous to period). Plots were truncated in order to avoid spurious frequencies.

Northern cores (around the core SU90-39) have a good similarity with GRIP (except for the last interglacial period, which is controversed in the Summit record [Grootes et al., 1993]). The "Dansgaard-Oeschger" events (numbered from 1 to 24) existing in the ice core are easily identified in marine records down to $110 \mathrm{ka}$. This reinforces the hypothesis of Bond et al. [1993] that the sea surface temperatures at the latitude of cores located between 50 and $55^{\circ} \mathrm{N}$ in the Northeastern Atlantic are in phase with the air temperature above Greenland.

In the southern area (around core SU90-08), the details of the reflectance signal appear less comparable with the Greenland record. Although similar in shape, this core does not show the same high-frequency variability as the Greenland record. Keigwin and Jones [1994] have detected a high 
variability in cores between $30-35^{\circ} \mathrm{N}$ and $60-70^{\circ} \mathrm{W}$. We can explain this difference with our results by the geographical location of their cores on an important area of sedimentation at great depth $(4900 \mathrm{~m})$.

Results of spectral analyses make possible the detection of various nonstationary climatic oscillations. The periodicities between 5 and $7 \mathrm{kyr}$ can be related to the Heinrich event glacial oscillations. The higher-frequency variability is in agreement with different model results of the general circulation of the ocean.

Sedimentary reflectance records provide a high temporal resolution proxy documenting displacements of the polar front. We show in this work that periodicities as low as $1.5 \mathrm{kyr}$ can be detected with high confidence in marine sediment cores. This corresponds to a thickness of $5-10 \mathrm{~cm}$ of sediment, given the mean sedimentation rate. Hence we can conclude that bioturbation does not completely smooth out the fast variations of paleoclimate. Our study therefore strongly supports the necessity of increasing sampling resolution from the traditionnal $5-10 \mathrm{~cm}$ to around $2 \mathrm{~cm}$ to record the climatic variability stored in deep ocean sediments. This will provide a 0.2 to $0.4 \mathrm{kyr}$ resolution in areas with $5-10 \mathrm{~cm} / \mathrm{kyr}$ of sedimentation rates.

Acknowledgments. The work on grey reflectance analysis was started in CFR, Gif with G. Bond's (LDEO, USA) guidance both for hardware and software, and we greatly appreciated his help. Improved software has been developed by F. Le Coat and N. des Cloiseaux for the sediment reflectance study. It is a pleasure to thank D. Paillard, E. Michel, J. Jouzel, F. Grousset, and J. C. Duplessy for useful discussions. G. Bond, T Hagelberg, K. Miller, and N. Pisias are to be greatly thanked for their constructive reviews. We are grateful to $M$. Arnold for AMS ${ }^{14} \mathrm{C}$ analyses; J. Antignac, B. Le Coat, and J. Tessier for isotopic analyses; and J. Tessier for technical assistance. The coring cruise Paleocinat I of the French R/V Le Surott was supported by Genavir and IFREMER. This work was initiated as a master's thesis in association with J. Y Reynaud. Basic support from CEA and CNRS to the CFR, program Geosciences Marines, and PNEDC from INSU is acknowledged. The isotopic analyses received support from the EU Environment program EV5VCT920117. This is CFR contribution $n^{\circ} 1722$.

\section{References}

Birchfield, G. E., and W. S. Broecker, A salt oscillator in the glacial Atlantic, 2, A "scale analysis" model, Paleoceanography, 5, 835-843, 1990.

Birchfield, G. E, and M. Ghil, Climate evolution in the PliocenePleistocene as seen in deep sea $\delta^{18} \mathrm{O}$ records and in simulations: Internal variability versus orbital forcing, $J$ Geophys. Res., 98(D6), 10,385-10,399, 1993.

Birchfield, G. E., H Wang, and J. J. Rich, Century/millenium internal climate oscillations in an ocean-atmosphere-continental ice sheet model, $J$ Geophys. Res, 99(C6), 12,459-12,470, 1994.

Bond, G., W. Broecker, R. Lotti, and J. MacManus, Abrupt color changes in isotope stage 5 in North Atlantic deep sea cores: Implications for rapid change of climate-driven events, in Start of a Glacial, edited by G J. Kukla and E. Went, NATO ASI Ser.13, pp. 185-205, 1992a.

Bond, G., et al., Evidence for massive discharges of icebergs into the North Atlantic ocean during the last glacial period, Nature, 360, 245$251,1992 \mathrm{~b}$.

Bond, G., W. Broecker, S. Johnsen, J. McManus, L. Labeyrie, J. Jouzel, and G. Bonani, Correlations between climate records from North Atlantic sediments and Greenland ice, Nature, 365, 143-147, 1993

Broecker, W. S., G. Bond, and M Klas, A salt oscillator in the glacial Atlantic?, 1, The concept, Paleoceanography, 5, 469-477, 1990.

Broecker, W. S., G. Bond, M Klas, E. Clark, and J. McManus, Origin of the northern Atlantıc's Heinrich events, Clim. Dyn., 6, 265-273, 1992.
Broomhead, D.S., and G.P. King, Extracting qualitative dynamıs from experimental data, Physica D, 20, 217-236, 1986.

Climate: Long-Range Investigation, Mapping, and Prediction (CLIMAP) Project Members, The last interglacial ocean, Quat Res., 21, 123-224, 1984.

Cortijo, E., J. C. Duplessy, L. Labeyne, H Leclaire, J. Duprat, and T. C. E. van Weering, Eemian cooling in the Norwegian Sea and North Atlantic Ocean preceding contınental ice-sheet growth, Nature, 372 , 446-449, 1994

Crowley, T. J., Calcium-carbonate preservation patterns in the Central North Atlantic during the last 150000 years, Mar. Geol., 5l, 1-14, 1983.

Dansgaard, W., H. B Clausen, N. Gundestrup, C. U. Hammer, S. F. Johnsen, P. M. Kristinsdottir, and N. Reeh, A new Greenland deep ice core, Science, 218, 1278-1277, 1982

Dansgaard, W., et al., Evidence for general instability of past climate from a 250-kyr ice core record, Nature, 364, 218-220, 1993.

Emıliani, C., Pleistocene temperatures, J. Geol., 63, 538-578, 1955.

Farge, M., Wavelet transforms and their applications to turbulence, Annu. Rev. Fluid Mech., 24, 395-457, 1992.

Gershenfeld, N. A., An experimentalist's introduction to the observation of dynamical systems, in Directions in Chaos, vol. 2, edited by H. Bailin, World Sci , River Edge, N.J., 1988.

Griggs, G. B., A. G Carey, and L. D. Kulm, Deep-sea sedimentation and sediment fauna interaction in Cascadia Channel and on Cascadia Abyssal plain, Deep Sea Res., 16, 157-170, 1969

Greenland Ice core Project (GRIP) Members, Climate instability during the last interglacial period recorded in the GRIP ice core, Nature, 364, 203-207, 1993.

Grootes, P.M., M. Stuiver, J W C. White, S. Johnsen, and J. Jouzel, Comparison of oxygen isotope records from the GISP2 and GRIP Greenland ice cores, Nature, 366, 552-554, 1993.

Grossmann, A., R. Kronland-Martinet, and J. Morlet, Readıng and understanding continuous wavelet transforms, in Wavelets: TimeFrequency Methods and Phase Space, edited by J. M Combes and P. Tchamitchian, pp. 2-20, Springer-Verlag, New-York, 1989.

Hagelberg, T K., G. Bond, and P. de Menocal, Milankovitch band forcing of sub-Milankovitch climate variability during the Pleistocene, Paleoceanography, 9, 545-558, 1994

Hays, J. D , J. Imbrie, and N. J. Shackleton, Varıatıons in the Eath's orbit: Pacemaker of the ice ages, Science, 194, 1121-1132, 1976.

Heinrich, H., Origin and consequences of cyclic ice rafting in the Northeast Atlantic Ocean during the past 130000 years, Quat. Res, 29, 142-152, 1988.

Hovine, S., Variabilité à long terme de la cırculatıon océanique mondiale: une étude à l'aide d'un modèle en équations prımitives à deux dimensions, Ph.D. thesis, $112 \mathrm{pp}$, Univ. Catholique de Louvann-laNeuve, Belgium, 1993.

Johnsen, S. J., H. B. Clausen, W. Dansgaard, K. Fuhrer, N. Gundestrup, C. U. Hammer, P. Iversen, J. Jouzel, B. Stauffer, and J. P. Steffensen, Irregular glacial interstadials recorded in a new Greenland ice core, Nature, 359, 311-313, 1992.

Keigwın, L. D., and G. A. Jones, Western North Atlantic evidence for millenial-scale changes in ocean circulation and climate, $J$. Geophys. Res., 99, 12,397-12,410, 1994.

Lindberg, C. R., Multiple taper spectral analysis of terrestrial free oscillations, Ph.D. thesis, 182 pp., Univ. of Calif., San Diego, 1986.

McManus, J. F., G. C. Bond, W S. Broecker, S Johnsen, L. Labeyrie, and $\mathrm{S}$. Higgins, High resolution climate records from the North Atlantic during the last interglacial, Nature, 371, 326-329, 1994.

Mitchell, J.M., An overview of climatic variability and its causal mechanisms, Quat. Res., 6, 481-493, 1976.

Paillard, D., Modèles simplifiés pour l'étude de la variabilité de la circulation thermohalıne au cours des cycles glaciaire-interglaciaire, Ph.D. thesis, 255 pp., Univ. de Paris-Sud, France, 1995a

Paillard, D., The hierarchical structure of glacial climatic oscillations: Interactions between ice-sheet dynarnics and climate, Clim. dyn., 11, 162-177, 1995b.

Peltier, W. R., Ice in the Climate System, NATO ASI Ser. I, 12, 653 pp., 1992.

Pestiaux, P., I. van der Mersch, and A. Berger, Paleoclimatic variability at frequencies ranging from 1 cycle per 10000 years to $I$ cycle per 1000 years: Evidence for nonlinear behaviour of the climate system, Clim. Change, 12, 9-37, 1988. 
Pisıas, N.G., JP. Dauphin, and C. Sancetta, Spectral analysis of late Pleistocene-Holocene sediments, Quat. Res., 3, 3-9, 1973.

Pısias, N.G., D.G. Martinson, T.C. Moore, N.J. Shackleton, W. Prell, J. Hays, and G. Boden, High resolution stratigraphic correlation of benthic oxygen isotopic records spanning the last 300000 years, Mar. Geol., 56, 119-136, 1984.

Ruddiman, W.F., and L.K. Glover, Vertical mixing of ice-rafted volcanic ash in North Atlantic sediments, Geol. Soc. Am. Bull, 83, 2817-2836, 1972

Shackleton, N. J., and N.D. Opdyke, Oxygen isotope and paleomagnetic stratigraphy of Equatorial Pacific core V28-238. Oxygen isotopes temperatures and ice volumes on a $10^{5}$ year and $10^{6}$ year scale, Quat. Res., 3, 39-55, 1973.

Slepian, S., Prolate spherordal wave functions, Fourier analysis and uncertainty-V: The discrete case, Bell. Syst. Tech. J., 57, 1371-1430, 1978.

Smythe, F W., W.F. Ruddıman, and D.N Lumsden, Ice-rafted evidence of long term North Atlantic circulation, Mar. Geol., 64, 13I-141, 1985.

Thomson, D. J., Spectrum estimation and harmonic analysis, Proc. IEEE, 70, 1055-1096, 1982.

Vautard, R, and M. Ghil, Singular spectrum analysis in nonlinear dynamics, with applications to paleoclimatic time series, Physica $D$, 35, 395-424, 1989.

Vautard, R., P. Yjou, and M. Ghil, Singular spectrum analysis a toolkit for short noisy chaotic signals, Physica D, 58, 95-126, 1992.
Welander, P., A simple heat salt oscillator, Dyn. Atmos. Oceans, 6, 233242, 1982.

Yiou, P., C. Genthon, J. Jouzel, M. Ghil, H. Le Treut, J. M. Barnola, C. Lorius, Y. N. Korotkevitch, High-frequency paleovariability in climate and in $\mathrm{CO}_{2}$ levels from Vostok ice core records, J. Geophys. Res., 96(B12), 20,365-20,378, 1991.

Yiou, P., M. Ghil, J. Jouzel, D. Paillard, and R. Vautard, Nonlinear variability of the climatic system from singular and power spectra of Late Quaternary records, Clim. Dyn., 9, 371-389, 1994.

Yiou, P., J. Jouzel, S. Johnsen, and O. E. Rögnvaldsson, Rapid oscillations in Vostok and GRIP ice cores, Geophys. Res Lett., in press, 1995.

E. Cortijo, Centre des Farbles Radioactivités (CFR), Laboratoire mixte CNRS/CEA, Avenue de la Terrasse, 91198 Gif-sur-Yvette, France. (email: Elsa.Cortijo@cfr.cnrs-gif.fr)

M. Cremer, Département de Géologie et d'Océanographie, Université Bordeaux I, Avenue des Facultés, 33405 Talence, France.

L. Labeyrie, Centre des Faibles Radioactivités and also Département des Sciences de la Terre, bât.504, Univ. Paris-Sud/Orsay, 91405 Orsay, France.

P. Yiou, Laboratoire de Modélisation du Climat et de l'Environnement, Département des Sciences de la Matière (DSM), CEA, L'Orme des Merisiers, 91191 Gif-sur-Yvette, France.

(Received December 12, 1994; revised June 20, 1995; accepted June 29, 1995) 